\title{
PROCESSOS CIVILIZADORES, COLONIALIDADES E DECOLONIALIDADES
}

\author{
CIVILIZING PROCESSES, COLONIALITIES \\ AND DECOLONIALITIES
}

\author{
PROCESOS CIVILIZATORIOS, COLONIALIDADES \\ Y DECOLONIALIDADES
}

Mauricio Antunes Tavares

Universidade Federal Rural de Pernambuco (Fundação Joquim Nabuco - FUNDJ), Recife/PE - Brasil

JoAna D'Arc De Sousa Lima UNILAB Universidade da Integração Internacional da Lusofonia Afro-Brasileira, Campus Redenção, Ceará

RESUMO A teoria dos processos civilizadores de Norbert Elias aporta um modelo analítico suportado por conceitos e noções, como figuração, interdependência, habitus, trajetórias, relação estabelecidos-novatos, entre outros. Mesmo não tratando diretamente das questões relacionadas à educação, elas aparecem como pano de fundo de seus estudos a respeito das sociedades europeias. Nosso ponto de partida é mostrar alguns usos das ferramentas desse modelo analítico nas pesquisas acerca da educação, escolarização e sobre juventudes. $\mathrm{Na}$ continuidade, apresentamos uma questão importante e atual que desafia nossos sistemas educativos: a crítica a um projeto educacional que é monocultural em sociedades compostas por grupos sociais diversos, em que as histórias e culturas dos povos originais e afrodescendentes são ignoradas. Esse problema revela alguns limites da teoria dos processos civilizadores. Como alternativa teórica para a pesquisa em educação discutimos os aportes do pensamento decolonial, teoria que vem sendo produzida por pesquisadores não europeus, especialmente latino-americanos. Os conceitos de colonialidade e de interculturalidade do pensamento decolonial geram propostas de enfrentamento ao eurocentrismo, em sua roupagem de projeto de modernidade, que seduz elites e classes sociais latino-americanas, mas que está a serviço da globalização neoliberal e ocidentalização do mundo.

Palavras-chave: Processo Civilizador; Civilização e Educação; Contexto Cultural; Crise de Paradigmas; Paradigmas Emergentes: Pensamento decolonial. 
Abstract Norbert Elias's civilizing process theory leans toward an analytic model constituted by concepts and notions, such as figuration, interdependency, habitus, trajectories, possibility fields, among others. Even if Elias does not deal with themes directly linked to education, they appear as background of his studies on Europeans societies. Our start point is to look into some uses of these analytic model tolls by researches on education, schooling and youth. From this we propose an important and up to date question which challenges our educational system: the critics on a monocultural educational project in societies constituted by a diversity of social groups, in which histories and culture of the original and afro-descendent people are ignored. This problem turns up some limits of civilizing process theory. As a theoretical alternative for educational research we have discussed the contributions of the decolonial thought, theory that has been produced by researchers non European, especially the Latin-American ones. The concepts of coloniality and of interculturality of the decolonial thought generate proposals for tackling euro-centrism, in its appearance of modernity project, that enchants Latin-American elites and middle class, nevertheless serves to the neoliberal project of civilization.

Key-words: Civilizing Process; Civilization and Education; Cultural Context; ParaDigm Crises; Decolonial Thought.

REsumen La teoría del proceso civilizatorio de Norbert Elias está apoyada en conceptos y nociones centrales, tales como figuración, interdependencia, habitus, trayectorias, figuración establecidos-forasteros, entre otros. Aunque Elías no se ocupa de temas directamente relacionados con la educación, aparecen como antecedentes de sus estudios sobre las sociedades europeas. Nuestro punto de partida es mostrar algunos usos de las herramientas de ese modelo analítico en investigaciones sobre educación, escolarización y juventudes. A partir de esto, proponemos una pregunta importante y actualizada que desafía nuestro sistema educativo: las críticas a un proyecto educativo monocultural en sociedades constituidas por una diversidad de grupos sociales, en que se ignoran las historias y la cultura de los pueblos originarios y afrodescendientes. Este problema plantea algunos límites de la teoría del proceso civilizador. Como alternativa teórica para la investigación, educativa hemos discutido las contribuciones del pensamiento decolonial, teoría que ha sido producida por investigadores no europeos, especialmente los latinoamericanos. Los conceptos de colonialidad y de interculturalidad del pensamiento decolonial generan propuestas para abordar el eurocentrismo, en su aspecto de proyecto de modernidad, que encanta a las elites latinoamericanas ya las clases medias, sin embargo sirve al proyecto neoliberal de civilización y occidentalización del mundo.

Palabras clave: Proceso Civilizatorio; Civilización y Educación; Contexto Cultural; Crisis de Paradigmas; Pensamiento decolonial.

\section{INTRODUÇÃo}

No sentido mais amplo do termo, educação é a forma como as gerações mais velhas introduzem as novas em um mundo já constituído, normatizado, repleto de patrimônios e 
repertórios diversificados de ideias, valores e práticas socioculturais consolidadas em diferentes sociedades. Como afirmou Hanna Arendt (1997), a educação seria como um novo nascimento, um nascer para o mundo social. Para Norbert Elias, a própria condição humana depende dessa aprendizagem coletiva:

[...] os seres humanos estão, por natureza, organizados de um modo que implica a aquisição, através da aprendizagem, de um fundo social global de conhecimento como condição para eles poderem orientar-se no seu mundo e manter a sua existência entre as outras existências (ELIAS, 2002, p. 76).

Os humanos povoaram o planeta aprendendo pela experiência e transmitindo-a em forma de conhecimento de uma geração a outra (ELIAS, 1998, p. 300).

Porém, a educação, como a entendemos hoje, é o termo cunhado em um período histórico recente, na transição da sociedade aristocrática para a sociedade burguesa moderna, como parte de processos sociais que modificaram sentidos, costumes e práticas sociais relacionados à família e à infância, como mostram os estudos de Phillipe Ariès (1981) e Norbert Elias (1998). Portanto, ao se referir à educação no âmbito da modernidade que se instaura a partir do século XVIII nas sociedades impactadas pela revolução industrial e pelo Iluminismo, particularmente os países europeus e a emergente nação dos Estados Unidos da América, exclui-se uma gama variada de formas de organizar e realizar a transmissão de conhecimentos, que fizeram e ainda fazem parte de repertórios culturais de diferentes povos, principalmente povos não europeus que resistiram aos processos colonizadores impetrados desde o norte ocidental em direção ao sul e ao leste.

As narrativas sobre o processo de expansão colonial dos países europeus difundiram durante muito tempo a ideia de que o predomínio europeu fundava-se na (suposta) superioridade de povos civilizados. Essa ideia era corrente até o início do século XX, época em que as ciências sociais ainda estavam em formação e se espelhavam nos paradigmas das ciências naturais, estudando as sociedades como se estas fossem organismos. Fazendo paralelo ao evolucionismo darwiniano, para formar uma ciência que chegou a ser nomeada como física social, os acadêmicos e as elites europeias acreditavam que as sociedades humanas estariam situadas em pontos diferentes de uma linha evolutiva única, e a posição que cada sociedade ocupava seria equivalente ao grau de evolução dos fatores biológicos característicos de cada tipo racial. Esse discurso transmitia a ideia de que os povos europeus tinham uma tarefa civilizadora para salvar o restante do mundo da ignorância, da barbárie e do inferno católico, uma vez que o homem e a mulher europeus, com seus hábitos e costumes refinados, erudição, bom gosto, alta cultura e desenvolvimento tecnológico superior, eram representantes do mais alto grau de evolução humana. Toda essa suposta superioridade e responsabilidade salvacionista diante dos "outros" era confirmada pela força destruidora dos seus exércitos sobre os "selvagens", como sendo a prova material dessa visão de si e do mundo. Justificava-se assim o empreendimento colonizador. 
A teoria dos processos civilizadores de Norbert Elias (1994a) foi cunhada primeiramente como crítica às falsas ideias de superioridade europeia que, ainda na primeira metade do século passado, alimentavam discussões acadêmicas e políticas pautadas nas noções de cultura (na Alemanha) e de civilização (na França). Mesmo não se referindo diretamente à educação e à escolarização em suas principais obras, é o modelo analítico da teoria dos processos civilizadores que tomamos como ponto de partida deste texto, a partir do qual intentamos problematizar o alcance e os limites do conceitual teórico-analítico de Norbert Elias para compreender os desafios atuais da pesquisa em educação e, por conseguinte, os desafios atuais da educação nas sociedades latino-americanas.

Particularmente, queremos confrontar o aparato teórico e metodológico do pensamento de Norbert Elias diante das questões relacionadas à diversidade cultural, que dizem respeito aos problemas educacionais gerados por sistemas escolares que são dominados pelos segmentos brancos, descendentes de povos europeus, em meio a sociedades formadas predominantemente por negros, índios e mestiços, que reivindicam não apenas a abertura de vagas em vários níveis desse sistema, a exemplo do sistema de cotas para ingressar no ensino superior público brasileiro, mas também a incorporação de suas histórias e conhecimentos, o que, no limite das tensões que essas reivindicações produzem, implicam a transformação do sistema.

Nesse caminho de reflexão sobre a educação e o sistema escolar construído no Brasil - cujo padrão não é muito diferente ao de outros países latino-americanos, pois todos foram construídos exclusivamente com base nos paradigmas de pensamento ocidental, considerando exclusivamente a epistemologia ancorada no racionalismo-cientificismo da experiência dos países europeus como única fonte de construção de conhecimento verdadeiro - vamos examinar propostas epistemológicas que surgem dentro das comunidades acadêmicas dos países latino-americanos, que estão sendo reconhecidas pelo nome de pensamento decolonial. Voltaremos nosso olhar para algumas contribuições vindas da América Latina, inclusive com influências de pesquisadores africanos e asiáticos, explorando as possibilidades que essas referências nos dão para o aprofundamento das pesquisas em torno das relações entre cultura, educação e sociedade.

Nossa intenção primeira é perceber o que poderemos ver e compreender, ao observarmos a realidade educacional brasileira e latino-americana ao utilizarmos cada uma dessas duas lentes. E, para tanto indagamos: Qual a contribuição delas para a pesquisa em educação e diante do desafio de (re)construir sistemas educativos (e políticos) mais democráticos e voltados ao atendimento das demandas e necessidades dos afro-brasileiros e povos indígenas que vivem entre nós?

Nessa trilha, desejamos também reconhecer a nossa necessidade de aprender com os conhecimentos e saberes dessas tradições não ocidentais, de buscar, em seus saberes, visões de mundo e modos de vida, outras possibilidades para o enfrentamento dos problemas sociais e ambientais que se agravam com a escalada de concentração de riquezas nas mãos de poucos, e de destruição da natureza em nome dessa mesma concentração. 
Já chegamos até aqui caminhando com os instrumentos que aprendemos no sistema escolar, todos eles ancorados na experiência e visão de mundo dos povos europeus, e os problemas que temos ainda, também são imagens refletidas dessa experiência. Procuraremos explorar as possíveis interfaces, colaborações e (in)compatibilidades entre a teoria dos processos civilizadores e o pensamento decolonial latino-americano emergente, para irmos adiante.

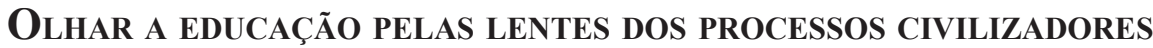

As formas de transmissão e construção de conhecimentos praticadas ao longo da História variaram de acordo com os diferentes contextos socioculturais e históricos de cada sociedade particular, e também de acordo com o conjunto de técnicas que essas desenvolveram, sendo a escrita apenas uma das formas, mas ainda assim sua ausência em alguns grupos sociais não interrompeu o processo de transmissão de conhecimentos. Ainda hoje, em muitos grupos sociais, a oralidade ocupa o centro do processo de ensino e aprendizagem.

No entanto, a partir do contato do europeu com o mundo "descoberto", cujos estudos fizeram avançar a antropologia, geografia, etnografia e outras ciências que, em seu desenvolvimento posterior, foram chamadas de Ciências Humanas e Sociais, o mundo europeu passou a ocupar o centro da história mundial, sendo o parâmetro comparativo para avaliar todas as outras sociedades, culminando, se é que se pode determinar-se um limite, no momento em que a escrita foi considerada o divisor entre a história e a não-história. Assim formulou Hegel (1999), em sua Filosofia da História, considerando que a África se dividia entre uma parte com história, a parte norte, por estar em contato com o mundo mediterrâneo, ou seja, com a Europa e o Oriente, sendo a África mesmo, a porção imensa do continente situada ao sul do Saara, uma África a-histórica.

Nesse contexto de colocar a Europa como "centro do mundo", a partir do empreendimento colonial que projetou os países europeus como conquistadores do novo e do velho mundo, do Sul e do Oriente, os processos de construção das ciências e do sistema escolar foram, ambos, conduzidos exclusivamente, dentro de uma mesma epistemologia, de uma mesma visão de mundo. Pressupôs-se que o "outro" foi conquistado por ser fraco, inferior e menos desenvolvido, e, por conseguinte, tudo que existia no mundo dele, afora as riquezas materiais, todo o repertório moral, espiritual, cultural e de conhecimentos também foram considerados inferiores e descartados.

A constituição do sistema educacional nas sociedades que viveram a experiência colonial e, no caso dos países americanos, acrescida da experiência escravagista, foi marcada por esse paradigma eurocêntrico, desde o ensino da língua do colonizador, como forma de extermínio cultural dos povos originários, até a conformação de um currículo que se espelhou estritamente nas ciências, excluindo uma variedade de conhecimentos e saberes tradicionais da oralidade. O código escrito impôs-se sobre a palavra dita e a escola foi sendo imposta como a instituição mais especializada em ensinar, entre as outras instituições que também ensinam. 
A importância da escola como agência de socialização e unificação nacional foi crescendo na mesma medida em que as sociedades que viveram as experiências colonial e escravagista foram se tornando mais complexas, com a diversificação das formas de divisão social do trabalho, entrecruzando aspectos territoriais da organização da produção agrária e industrial, com questões étnico-raciais e de classe social. As figurações sociais americanas, especialmente das sociedades latino-americanas, foram se constituindo nesse amálgama do racismo e da desvalorização dos trabalhos manuais por associá-los à condição do escravo. O desenvolvimento dos sistemas produtivos nas sociedades latino-americanas -, e as mudanças profundas experimentadas nas estruturas sociais e econômicas, em função da industrialização e de suas consequências sobre a vida urbana, elevaram aquela que até então existia como instituição das elites, dedicada a ensinar artes, ofícios e boas maneiras, a escola, ao nível de instituição imprescindível à organização das sociedades modernas.

À semelhança do que já acontecera na Europa, também nas sociedades latinoamericanas, depois de três séculos de colonização, a escola deixa de ser uma instituição particular e atrelada às igrejas e se incorpora ao aparelho estatal, entre meados do XIX e início do XX, para melhor cumprir as funções de unificação e pacificação política, consolidando a formação das identidades nacionais (ELIAS, 2014a), e de preparação da força de trabalho para a expansão da empresa capitalista (CANÁRIO, 2005). Cada vez mais o Estado nacional vai "assumindo a maioria das funções anteriormente atribuídas às comunidades, em um processo de desfuncionalização da vida comunitária” (GEBARA, 2011, p. 21), o que inclui a tarefa de formar as novas gerações.

Nem os processos de independência, nem as nascentes repúblicas latino-americanas interromperam o que foi implantado pelo processo colonizador. A violência, física e simbólica, para o controle necessário à dominação e exploração dos povos originários e populações de mestiços, teria continuidade por intermédio das instituições punitivas e educativas. Aos rebeldes, as instituições militares e judiciais dariam cabo, esmagando inúmeros levantes, revoltas e revoluções. E para pacificar as multidões, enquanto a igreja tratava de converter mentes e corações, a escola tratava de formar bons cidadãos.

Em estudo sobre a natureza civilizadora do processo de colonização e formação da população brasileira, Ademir Gebara (2011), ao trazer à luz documentos produzidos pela Igreja Católica e, posteriormente, pelo Estado imperial brasileiro, revela que o principal interesse das ações de catequização e educação levadas aos índios tinham o sentido de domesticação, ou seja, tornar o índio amigável, familiar, confiável aos olhos do colonizador. Isso implica, de um lado, distinguir os índios amigáveis dos índios bravios, ou seja, identificar potenciais aliados e assimiláveis e, de outro lado, potenciais inimigos não assimiláveis. E, a assimilação não era outra coisa senão a de transformar índios em caboclos, agricultores sedentários que viveriam em aldeias, ou povoados, e praticariam uma agricultura de subsistência, mas importante, tanto pela manutenção da unidade familiar, quanto pelo excedente que acabaria abastecendo o mercado local.

O índio bravio, que mora na mata, no sertão, é o índio que não aceita a assimilação e se torna, portanto, inimigo da civilização, elemento pernicioso que deve ser afastado, pois 
pior do que o arco e flecha é a disposição dele para lutar contra o colonizador, cujas armas eram muito mais mortíferas que a dos índios, o pior era o seu apego ao modo de vida indígena, que fortaleceria a resistência de outros índios. Esse modo de vida, essa cosmovisão ameríndia, eram os inimigos mais perigosos, pois que representam a antítese do projeto civilizador. Por isso, era necessário a igreja e suas escolas.

As missões e aldeias jesuítas, assim como as escolas, eram lugares para ensinar, além da língua e do cálculo matemático, elementos essenciais que formam uma base comum para a transmissão de conhecimentos e formação de uma identidade. Por meio de cânticos, jogos, festas e outras diversões, construíram ambientes para gerar empatia entre colonizadores e colonizados, e a empatia daria oportunidade à conquista das mentes, à conversão dos índios e à assimilação das práticas sociais estrangeiras. Havia também o ensino de práticas artesanais e ofícios, e assim criavam oportunidades para um pequeno, mas significativo, número de índios que se integrariam ainda mais ao projeto colonizador, na condição de trabalhadores.

Essa é a escola rural que perdurou até meados do século XX, a escola que fazia, muito mal e limitadamente, a educação dos filhos e filhas de um país cuja maioria esmagadora da população vivia no campo. A partir de 1910, a intenção de industrializar o país torna-se obsessão para as elites paulistas, que, com os mineiros, alternavam-se na presidência do país; porém, foi somente com a destituição desses pelo golpe de Estado chamado Revolução de 1930 que esse projeto ganhou mais fôlego, motivando intensos debates sobre a necessidade de reformar a educação pública, e massificá-la, com a finalidade de preparar a mão de obra que migraria para as cidades a fim de trabalhar nas indústrias. É nessa condição de agência de apoio à modernização capitalista que a escolarização das populações rurais do Brasil passa a ser valorizada pelas elites dirigentes.

Em pesquisa realizada no campo da história e memória da educação e dentro dos paradigmas da sociologia das configurações, Tavares (2014) discorre sobre algumas das formas pelas quais o projeto educativo da Escola Rural Alberto Torres, situada nos arredores da cidade do Recife, modernizava os ideais civilizadores ainda presentes na educação escolar brasileira nos anos 1930-1940. Muito embora tivesse sido influenciado pelas ideias escolanovistas que se espalhavam pelo país a partir da atuação de eminentes educadores e gestores públicos, como Anísio Teixeira e Fernando de Azevedo, essa escola, inaugurada em 1935, atuou como centro de formação de professoras para a educação rural por mais de vinte anos, e teve muita influência no panorama estadual e nacional no debate em torno de qual projeto de educação rural era adequado para o desenvolvimento nacional. Há registros publicados em revistas e jornais da época mostrando as diretoras da escola desse período participando em congressos nacionais de educação rural, em encontros de professores, em eventos solenes, muitos na própria escola, com autoridades e intelectuais do país. Mantinha parceria com a Associação dos Amigos de Alberto Torres, no Rio de Janeiro, cuja missão era propagar os ideais da educação ruralista que o falecido sociólogo defendia nos anos 1910-20, e essa associação distribuía cerca de 100 exemplares do jornal mensal que a escola editava, contribuindo para divulgar a instituição escolar em nível nacional, conforme mostram os registros de correspondências que eram divulgados em cada número. 
A observação das ações pedagógicas dessa escola, documentadas em artigos jornalísticos, acadêmicos e no jornal escolar $O$ Semeador, editado pelo Clube Agrícola da escola e com exemplares preservados do período de 1935 a 1942, mostra que essas eram repletas de conteúdos de higiene e saúde. Esses dois campos estavam articulados em um mesmo Ministério, no governo de Getúlio Vargas, e isso tinha uma intencionalidade política. Nessa época, as imagens socialmente construídas sobre o camponês o associavam à precariedade, à ignorância, à doença e à indolência, como o personagem Jeca Tatu, de Monteiro Lobato, que se parece com o personagem do conto vencedor do concurso escolar do ano de 1935:

\begin{abstract}
Pedrinho Deixou de Ser Preguiçoso
Existia num sitio uma família da qual fazia parte um menino: o Pedrinho.

Pedrinho era um menino muito preguiçoso, mas gostava dos animaes e protegia muito as arvores.

Elle não era mau e parecia até intelligente. Elle vivia com seus paes, mas, esses eram muito descuidados, alem de pobres. As crianças apanhavam fructas do chão e comiam sem lava-las. O seu quintal era sujo, não cuidavam nem de retirar o lixo. Quando iam á mesa não lavavam as mãos. Os paes pobres e ignorantes nunca se lembraram de construir uma latrina perto da casa. Emfim não sabiam o que significava a palavra: hygiene. $\mathrm{O}$ menino andava descalço no quintal sujo, penetrando assim os vermes em seu organismo.

Um dia a professora deu uma aula sobre os vermes que penetram no corpo de quem vive descalço. Todos devem saber que os pés possuem poros, por onde penetram os vermes, fazendo as pessôas ficarem pálidas e preguiçosas. Disse a mestra aos meninos, que tomassem um vermifugo. Pedrinho foi á pharmacia e comprou este remedio. O vermifugo foi a verdadeira salvação.

Engordou e tornou-se corado, forte e sadio. Hoje, anda calçado, construiu no quintal uma latrina, lava as mãos varias vezes por dia e só come fructas e verduras bem lavadas.
\end{abstract}

Educar, nesse contexto, adquiria os sentidos de civilizar e de sanar os rurais das mazelas que assolavam o campo. A essência das práticas educativas desenvolvidas na Escola Rural Alberto Torres estava na transformação dos modos de fazer e costumes dos rurais, utilizando a educação moral e a higiene para formar o "novo homem do campo", mais saudável e mais produtivo. Igualmente, formar o novo operário, que vai migrar rumo às cidades, em busca de oportunidades de trabalho e melhores condições de vida.

Os êxitos que o higienismo lograra nas intervenções urbanas eram alardeados de diversas formas, em reportagens, livros, teses, receituários médicos, nas produções artísticas e propagandas políticas. No entanto, o mundo rural ainda era um grande desafio a ser enfrentado (MOTA, 2010; MARQUES, 1994). A higiene é apresentada como elemento indicador do grau de civilização da pessoa/grupo social em questão, no caso, os agricultores. Nos conteúdos abordados na escola, relatados no referido jornal escolar, a higiene também aparecia como disciplina científica, de base biológica e com atributos morais, fazendo das intervenções sociais seu maior campo de aplicação. 
Tratava-se, então, de dar continuidade ao processo civilizador iniciado com a transformação dos índios em agricultores, nos séculos da colonização e do Império, para, já no final do século XIX e início do XX, transformar os filhos dos caboclos em operários. Como a escola jesuíta fazia com os índios, "Nesse contexto, a missão da escola, como agencia socializadora, era sanear e civilizar as populações do campo, alcançando os adultos por intermédio da educação das crianças" (TAVARES, 2014, p. 155).

Um efeito não desejado e imprevisto dessa valorização do papel da escola na (trans)formação da sociedade foi o aumento da pressão social pela expansão e qualificação do sistema escolar. Esse é o caso dos povos indígenas, assim como dos demais grupos sociais que vivem no campo, todos reivindicando o direito de estabelecer um projeto político-pedagógico próprio e distinto, dentro do sistema público de educação, mas com autonomia para definir currículo, alterar as formas organizativas e as práticas pedagógicas, modificando temporalidades e espaços de ensinar na relação entre a escola e a comunidade. Como se diz entre os povos indígenas brasileiros: para se formar um guerreiro, é preciso uma aldeia inteira.

$\mathrm{O}$ caminho da massificação da escola no século XX foi trilhado primeiramente nos países europeus, ainda na primeira metade do século (CANÁRIO, 2005) e, no caso do Brasil e de outros países latino-americanos, somente na segunda metade do século é que foi concretizado.

Em pesquisas sobre jovens, Tavares $(2010,2011)$ observou essa pressão por uma educação de qualidade por parte de jovens de um pequeno município do sertão pernambucano, que experimentava o renascimento da economia agrícola a partir da recuperação de um assentamento irrigado que, na época, em 2004, tinha quase duas décadas em que o projeto fora abandonado. No relato da pesquisa, o autor afirma que era um momento de retorno de jovens casais, com filhos, que migraram para outras cidades e regiões em busca de trabalho e que retornavam para trabalhar na terra e deixar de ser "sujeitado", como se referiam ao trabalho assalariado. Nesse contexto, a sociabilidade gerada entre os jovens adultos retornados da migração e os adolescentes e jovens mais novos gerou dúvidas e debates entre eles quanto à durabilidade do novo ciclo de agricultura irrigada e, por conseguinte, sobre a viabilidade em continuar vivendo ali, ou se seria melhor ainda apostar na migração, temporária ou definitiva, como estratégia de inserção no mundo do trabalho e conquista de autonomia financeira.

Segundo o autor, a possibilidade de ficar e trabalhar no município, seja na agricultura, na piscicultura (que era novidade no local), seja no minúsculo setor de serviços e comércios motivava a busca por uma educação melhor, que fornecesse bases para o jovem desenvolver suas ideias e projetos. As oportunidades foram aumentando com a chegada de projetos socioeducativos iniciados por sindicatos e organizações não governamentais que buscavam o engajamento dos jovens. A escola se viu questionada pelos jovens que participavam desses projetos, pois estes vivenciaram processos educativos que não dissociavam prática $\mathrm{e}$ teoria, justamente o oposto do que experimentavam na escola, que parte da separação entre saber e fazer. A tensão entre a escola e os jovens que viveram outras experiências significativas de aprendizagem está refletida no depoimento que tomamos da pesquisa: 
Às vezes as pessoas falam: "fizeram sua cabeça pra você gostar dessas coisas". Eu também penso às vezes: será que foi isso mesmo? Será que eu estou sendo... o pessoal tá mudando as minhas ideias? Mas não, eles em momento nenhum falaram "vá, faça isso, faça aquilo, isso não". Eles ensinaram a gente a querer mais, eles ensinaram a gente a olhar pra nosso interior. Saber o que se passa na nossa cabeça, assim, raciocinar mais, refletir mais. Eu passei a refletir (Evaldo, 20 anos de idade, digitador, mora na cidade) (TAVARES, 2010, p. 342).

Assim, novas experiências de construção de conhecimento contribuíram para a diversificação dos padrões de relações entre os jovens, a escola e a comunidade, ampliando o campo de possibilidades que esses têm para trilhar suas trajetórias, mas também gerando tensões e conflitos. Como adverte Elias:

\begin{abstract}
$\mathrm{O}$ estreitamento e o alargamento
das oportunidades de vida, das oportunidades de significado em geral e das oportunidades de carreira em particular, para as gerações mais jovens de uma sociedade em qualquer época são processos que, sem dúvida, afetam mais fortemente o equilíbrio de poderes entre as gerações. Poder-se-ia dizer que esses processos constituem o núcleo dos conflitos sociais entre as gerações (ELIAS, 1997, p. 221).
\end{abstract}

Embora a questão das gerações e da juventude já ter sido objeto de análise de outros teóricos, inclusive de Mannheim, de quem Elias foi orientando, Elias é quem fez a formulação teórica mais consistente e elucidativa das condições em que os conflitos geracionais podem provocar mudanças sociais mais ingênuas, que ora não consideravam que a sucessão de gerações poderia provocar mudanças sociais mais profundas, visto que os jovens tenderiam a repetir as ideias e comportamentos em que foram socializados, ora consideravam a juventude como "naturalmente" revolucionária, por sua natureza rebelde e contestatória.

A reflexão de Elias sobre a questão da juventude e dos temas e questões intergeracionais é extremamente importante para o estudo das relações entre educação, trabalho e formação das novas gerações. Ele coloca de maneira clara que a possibilidade de mudança social, ou de continuidade das ideias e comportamentos transmitidos, depende, justamente, das relações entre as diferentes gerações que habitam no mesmo tempo histórico, na mesma sociedade e, portanto, vivenciam problemas semelhantes, mas em condições e com sentimentos diferenciados, e a depender dessas circunstâncias, pode gerar conflitos intergeracionais que podem provocar mudanças (TAVARES, 2017). É importante remeter à noção fundamental de que a força, o poder, é atributo de todas as relações sociais, e que o (des)equilíbrio de poder, a depender do contexto, pode ser instável e dar oportunidade às mudanças nas relações.

Em pesquisas sobre a juventude, Tavares $(2010,2011,2017)$ utiliza as noções de campo de possibilidades e de trajetória, construídas a partir do que Elias observou sobre a formação do habitus social dos indivíduos, especialmente nas obras em que ele buscou compreender as figurações sociais, e conflitos e lutas presentes nestas, com base em estudo 
de trajetórias individuais, como nas obras: Mozart, sociologia de um gênio e A peregrinação de Watteau à Ilha de Cítera. No método eliasiano de examinar a biografia do músico e a "biografia" de uma obra de arte, os eventos, acontecimentos e fatos aparentemente individuais, particulares, são compreendidos à luz de relações interdependentes entre estes, a aristocracia, a burguesia nascente, as (re)configurações dos campos da música e das artes, emaranhadas as vicissitudes e ocorrências da vida cotidiana, resultando, então em trajetórias cujos sentidos e significados não estão no controle de qualquer dos sujeitos envolvidos, nem mesmo deles próprios.

O estudo das trajetórias individuais permitiu a Elias compreender, no nível micro, como se entrelaçam os fios da reprodução e da diferenciação social na vida dos indivíduos que, portanto, nem são determinados pelo coletivo, nem são seres independentes do coletivo, são pessoas que produzem a si mesmas simultaneamente e em interdependência com os processos de produção do "social". É assim que pessoas pertencentes a um mesmo grupo social, submetidas aos mesmos processos de socialização e partilhando de elementos comuns com o coletivo, por mais homogêneo que seja o grupo, vão apresentar trajetórias diferenciadas, pois as ideias, as práticas e escolhas de cada indivíduo vão depender "sempre da natureza das relações entre ela e as outras pessoas" (ELIAS, 1994b, p. 27; 150).

Assim, o que se entende por campo de possibilidades não pode ser confundido como uma lista de vagas de trabalho ou de cursos, como uma oferta de oportunidades concretas e acessíveis à qualquer um, mas como um campo de jogo, que será explorado de modo diferente de acordo com as relações sociais entre os distintos sujeitos, relações permeadas por interesses, capacidades e condições de engajamento ou distanciamento estabelecidas. E é isso que faz as trajetórias individuais serem diferenciadas, mesmo em grupos sociais muito homogêneos, apesar de não se desvencilhar de algumas marcas que vêm dos constrangimentos estruturais que pesam sobre o grupo social de origem.

Esse mesmo caminho metodológico também foi trilhado por Lima (2014), numa investigação sobre a formação de novos artistas, no contexto da cidade do Recife dos anos 1980. O estudo, que resultou em tese de doutorado e livro publicado, produziu uma cartografia das várias formas, espaços e temporalidades educativas e culturais que, articulados na própria dinâmica das relações sociais estabelecidas, culminaram na formação de uma nova geração de artistas na arte contemporânea brasileira. O caminho da pesquisa também foi o de entender as relações de interdependência entre trajetórias de pessoas e coletivos com a configuração do campo da arte contemporânea na cidade do Recife nos anos 1980, que também está em relação com todo o contexto sociopolítico e cultural da época. Dessa forma, a pesquisa assinala o que Elias diz sobre o combustível das mudanças sociais provocadas por conflitos geracionais: a geração mais velha domina as oportunidades sociais e se transforma em um bloqueio para o acesso da nova geração a essas mesmas oportunidades. Diz a autora:

É importante este estudo [Mozart,] pela forma como relaciona este universo da experiência vivida e subjetiva com o contexto funcional da sociedade de corte. É esta relação que vejo nas trajetórias desse grupo de recifenses que despontou no meio artístico nos anos de 1980. [...] Vivem mais intensamente os proces- 
sos políticos, a liberdade, o prazer e o exercício dos experimentalismos, como tônica em sua atuação, como respostas às barreiras que dominavam a política nacional e o meio social. O meio artístico local, que não oferecia a possibilidade regular de expor realizações dos artistas já estabelecidos, muito menos dos jovens artistas, se reconfigura com a emergência desses artistas, pelas suas relações entre si e deles com o meio político-social e com a própria cidade. Dessa forma, a carência de espaços expositivos e a timidez das políticas culturais, aliadas a uma hegemonia no campo artístico - campo de luta e de legitimidades construidas pela disputa de poder -, transforma-se no combustivel que vai girar a roda dos experimentalismos e das iniciativas que buscam romper com tradições e lugares consagrados de exposição (LIMA, 2014, p. 127, grifos do autor).

Esses caminhos investigativos das pesquisas aqui abordadas corroboram com a explicação de Chartier sobre o cerne da teoria de Elias:

[...] Elias coloca como centrais as redes de dependências recíprocas que fazem com que cada ação individual dependa de toda uma série de outras, porém modificando, por sua vez, a própria imagem do jogo social. [...] para Elias são as variáveis que estão em jogo, os fios diversos e as muitas possibilidades criadas em cada uma das cadeias de interdependência - que podem ser mais ou menos longas, mais ou menos complexas, mais ou menos coercitivas - que vão tecendo o suporte que define a especificidade de cada formação ou figuração social (2001, p. 13).

É com essas referências teóricas e metodológicas do pensamento de Norbert Elias que, nos estudos sobre a educação e escolarização, podemos compreender as relações entre a formação das subjetividades e identidades coletivas, e os processos sociais de longo prazo que moldam as estruturas sociopolíticas da sociedade e, por consequência, modelam as relações entre os grupos sociais que fazem parte de uma mesma sociedade geral, como Elias demonstrou em obras como A sociedade de corte, e, Os estabelecidos e os outsiders, entre outras. A sociologia dos processos de Elias nos permite revelar os caminhos das formações sociais atuais, entendendo-as como resultados de articulações concretizadas e, por conseguinte, de possibilidades rejeitadas e derrotadas.

Em estudos históricos que buscam reconstituir a memória das instituições escolares, ou em estudos do presente sobre formação de professores, práticas pedagógicas, trajetórias de instituições educativas ou trajetórias individuais, em estudos a respeito das mudanças sociais, juventudes e conflitos geracionais, em estudos macro, ou micro, o aparato teórico do pensamento de Norbert Elias nos permite investigar o processo de formação daquilo que hoje, olhando como se fosse para uma fotografia, muitos ignoram as operações que foram feitas anteriormente e que resultaram nas configurações sociais que conhecemos e, principalmente, no que somos hoje. E talvez o que mais contribui para essa percepção seja, justamente, o trabalho de inculcação da racionalidade científica e da lógica da modernidade urbano-industrial realizado pela escola. 


\section{Escola, CULTURA E OCULTAMENTOS}

Como parte indispensável do projeto da modernidade, a escola contribuiu para o apagamento dos processos sociais que construíram o edifício das ciências, tal qual nós o conhecemos hoje, compartimentado em disciplinas, cuja divisão reflete certas lógicas e lutas de poder entre cientistas em determinados contextos históricos. Por meio do currículo, a escola contribui para o duplo apagamento de que falam Bourdieu e Passeron (2008): apagar os processos de seleção dos conhecimentos a ser ensinados, que impuseram a epistemologia racionalista científica como a única produtora de conhecimentos válidos a ser ensinados pelo sistema escolar, e apagar esse processo de apagamento, para que tudo que está tenha a aparência de que não poderia ser diferente.

Oculta-se que a escola, como hoje nós a conhecemos, resulta de processos de seleção e escolhas: dos conhecimentos ditos científicos entre as outras formas de conhecimentos e saberes que circulam no mundo; de uma forma de organização entre várias formas de organizar o tempo e o espaço de ensinar; de uma divisão disciplinar, fragmentada e hierarquizada dos conteúdos a ensinar, entre outras possibilidades de aprender sobre a natureza e a sociedade de maneira mais integrada; de modos de avaliar e certificar o mérito dos estudantes, entre outras formas de avaliar e certificar o caminho educativo que cada um escolhe e consegue realizar.

Nas sociedades contemporâneas forjadas nos processos de colonização - americanas, africanas e asiáticas -, esse ocultamento é latente no currículo escolar, que ignora completamente as histórias e culturas dos povos originários, e mesmo as lutas e os modos de viver dos habitantes ancestrais que lutaram contra a dominação colonial. Iluminam determinados fatos, eventos e personagens para criar uma narrativa que é ficcional, apesar das provas materiais de que um dia existiram realmente, pois, envolto em nuvens espessas e escuras esconderam outros fatos, eventos e personagens que estavam resistindo à invasão. São todos ossos secos escondidos no subterrâneo de catacumbas abaixo das catedrais, monumentos e edifícios coloniais, ou, simplesmente, viraram cinzas queimados pelo fogo.

Resulta disso a total ignorância do sistema escolar sobre as culturas e os saberes populares e, por consequência, a hostilidade institucionalizada, porém discreta, do sistema escolar sobre os sujeitos que, vindos das camadas populares, demonstram dificuldade em se integrar e aprender, na forma como a escola realiza a transmissão de conhecimentos.

Sousa (2003, p. 109-111), em estudo sobre o racismo nas escolas brasileiras, revela como este se oculta nas linguagens escolares subjacentes, entendidas como "formas de comunicação aparentemente ingênuas e isentas de ideologias, mas que estão, de fato, impregnadas de preconceitos". São imagens sociais construídas em textos, cartazes, peças de teatro, brincadeiras, músicas, paródias, gincanas, concursos etc., que colocam os negros em situações de inferioridade e degradação. Ou, ainda, situações ou materiais pedagógicos adotados que ignoram a existência dos negros. Um exemplo dessas duas situações pode ser encontrado nos livros didáticos: há livros que colocam imagens sobre a escravidão, miséria e situações em que os negros sempre aparecem inferiorizados, e há livros que, sim- 
plesmente, não têm imagem de negros, só de brancos. E ainda há a própria linguagem dos professores e outros membros da comunidade escolar que evitam falar que o aluno ou aluna é negro/a, substituindo por termos como moreno/a, bronzeado/a, pardo/a, escurinho/a.

Ademais, Sousa (2005) ainda encontrou, em sua pesquisa nas escolas públicas, muitas situações de interações em que o racismo se expressa em palavras e atos, mas é considerado como parte das brincadeiras e da sociabilidade juvenil, não sendo levado a sério.

\footnotetext{
Nesse sentido, a sala de aula e a escola como um todo tem se caracterizado como um espaço de conflito no qual as crianças e adolescentes, negras e negros, sentem dificuldade de consolidar, positivamente, sua identidade e sua autoestima. Isto dá-se, principalmente, pela costumeira vinculação do negro com situações ou coisas pejorativas, através de apelidos e comparações grosseiras e desagradáveis (SOUSA, 2005, p. 112).
}

Ao ignorar a presença e as culturas das populações afrodescendentes e dos povos indígenas, a escola contribui para esse processo social de negação das identidades e dos direitos coletivos desses que constituem, no Brasil e em muitos países, a maioria da população. É como se esses grupos sociais não tivessem produzido conhecimentos, saberes, artes e fazeres que pudessem ser ensinados nas escolas. É como se esses povos não tivessem nada que valesse a pena estudar. A escola, monocultural, somente organizada sobre fundamentos racionalistas e cientificistas, torna-se, dessa forma, agência de reprodução de desigualdades sociais, já mostraram diversos autores e autoras.

Mas, essa dimensão da escola como agência de reprodução social está entranhada em sua história e se manifesta em diferentes aspectos. Primeiramente, a escola reproduz conhecimentos que foram construídos extramuros: seleciona os conhecimentos científicos em detrimento das outras formas de conhecimento e, entre os conhecimentos científicos, seleciona e hierarquiza aqueles que serão ensinados, como mostram Bourdieu e Passeron (2008), na clássica obra $A$ reprodução, e o trabalho de Pérez Gómez (1998) sobre a função social da escola.

Mesmo em disciplinas não científicas, como no caso das artes visuais, música e literatura, os processos de ensino escolares se apoiam nos conhecimentos construídos externamente e também acabam por reproduzir sistemas de classificação desses campos, como a diferenciação entre o erudito e o popular.

A escola reproduz a lógica racionalista-científica também ao hierarquizar os conhecimentos a partir de sistemas classificatórios externos e reafirma a distinção arbitrariamente estabelecida nesses campos entre o que é considerado mais relevante e menos relevante pelas autoridades que formam cada campo. No sistema escolar, os conhecimentos científicos são considerados mais relevantes que os conhecimentos da cultura e das artes, e a distribuição do número de aulas que cada disciplina deve ter no currículo é prova desse julgamento. Entre os conhecimentos científicos, o domínio da língua escrita e da matemática é mais relevante que os conhecimentos das ciências sociais.

E, assim, a escola exercita outra forma de reprodução, dos sistemas de classificação produzidos em campos externos, e que são, em suma, visões de mundo, modos de com- 
preender a realidade, de avaliar e de se posicionar sobre a realidade. Sistemas que foram formados, em sua maioria, em sociedades europeias, com base em critérios de julgamento e gosto estético, forjados historicamente desde as sociedades de corte até a formação das sociedades burguesas industriais (BOURDIEU, 2007; ELIAS, 1994a). A escola assume a racionalidade eurocêntrica, que produz hierarquizações assimétricas tomando como única verdade a que é fruto da racionalidade científica (ABRAMOWICZ e GOMES, 2010).

Dessa forma, a escola reafirma a subalternidade dos currículos que tratam da cultura, do popular, dos conhecimentos e saberes originados em racionalidades não científicas, em povos não ocidentais. $\mathrm{O}$ que o sistema escolar das nossas sociedades toma como sendo o mais relevante, o que é importante a ser ensinado, é justamente aquilo que está relacionado ao modo de pensar e de viver do colonizador, que é tomado como sendo o seu próprio modo de pensar. A escola praticamente ignora o que deveria ser a primeira lição a ensinar aos jovens já alfabetizados:

Devemos, pois, ler os grandes textos canônicos, e talvez também todo arquivo da cultura europeia e americana pré-moderna, esforçando-nos por extrair, entender, enfatizar e dar voz ao que está calado, ou marginalmente presente ou ideologicamente representado em tais obras (SAID, 1995, p. 104).

E aí é evidente alguns dos efeitos do papel reprodutor da escola: ela reproduz a estrutura social de sociedades que foram formadas sob a influência do eurocentrismo e, desta faz, reproduz as hierarquias de classe e status, de gênero e étnicas, pois são estas que mais fortemente decorrem da visão de mundo que sobreviveu ao fim do colonialismo e estão presentes em várias manifestações de nossa sociedade: no patriarcalismo, no machismo, no elitismo e no racismo que permeiam as relações sociais do cotidiano.

Ao reproduzir e disseminar ideologias e conceitos que desvalorizam o grupo negro, o sistema educacional garante às crianças e aos adolescentes negros um tipo de tratamento que dificulta e até mesmo chega a impedir a sua permanência na escola e/ou o seu sucesso escolar (CAVALLEIRO, 2005, p. 68).

A escola construída nas sociedades brasileiras e latino-americanas é secularmente discriminatória, excluindo sujeitos e negando as identidades, conhecimentos e cultura afrodescendentes e dos povos originais. Difundindo "visões distorcidas e socialmente construídas, sobre determinados grupos ou segmentos sociais, podem vir a ser apresentadas e apreendidas como verdadeiras, inatas, causando prejuízos consideráveis aos sujeitos vitimados pelo preconceito" (SOUSA, 2005, p. 117).

Ao funcionar como reprodutora de conhecimentos e estruturas sociais, a escola produz outras desigualdades, geradas intramuros, visto que também constrói um sistema de avaliação, classificação e certificação de mérito que somente ela aplica, mas que também é universal, reconhecido por outras instituições, das repartições públicas às empresas privadas, e transcende fronteiras, dos lugares rurais às megalópoles globais. 
Esse dispositivo particular à escola, esse seu poder de classificar e certificar produz ilusões e desilusões nos diferentes grupos sociais, mas especialmente nos pobres, que vão se esforçar para que seus filhos estudem na esperança de melhores dias. Isso por causa dos casos desviantes em relação à lógica de reprodução social: estudantes que têm origem nos grupos sociais subalternos (operários, camponeses, minorias étnicas, migrantes, pequenos comerciantes etc.) eventualmente experimentam algum tipo de ascensão social após conquistarem títulos meritocráticos conferidos pelo sistema escolar. Também acontece a inversão dessa lógica, ou seja, estudantes pertencentes às elites dominantes poderão sentir alguns efeitos limitadores de mobilidade social por não conseguirem um resultado satisfatório na trajetória escolar, como demonstraram Bourdieu e Passeron (2008). E a combinação desses desvios produz o efeito discursivo de que a escola é democrática e oferece as mesmas condições para todos, ocultando os problemas que gera tratar com igualdade pessoas que são diferentes e desiguais.

Porque, por detrás da suposta igualdade de condições que a escola oferece a todos os alunos, as condições de origem social e as condições de permanecer e ter uma trajetória escolar satisfatória não são idênticas para brancos e não brancos. Mesmo quando as condições de origem social são semelhantes entre os distintos grupos de estudantes, serão os negros e indígenas os mais prejudicados, considerando questões estruturais da educação brasileira, como constatou Cavalleiro (2005, p. 69): "Aspectos do cotidiano escolar como currículo, material didático e relações interpessoais são hostis e limitadores de aprendizagem para os(as) alunos(as) negros(as)".

Por isso, por esse poder de distinção simbólica que a escola possui, o sistema escolar torna-se palco de disputas entre projetos políticos divergentes, que pendem ou para uma maior democratização da escola, implicando em adotar dispositivos que aumentem o acesso à escola, ou que modifiquem currículos, modos de ensinar, avaliar, certificar etc., ou para a elitização da escola, reforçando a seletividade e a meritocracia como bases de organização da sociedade.

Mergulhados nos ideais, ideias e pressupostos do projeto de modernidade, com suas influências iluministas, as sociedades que emergiram do sistema colonial, consagrando a racionalidade técnico-científica como forma hegemônica de conhecimento e de subjetivação, experimentam também o processo de individualização profunda que marca nosso tempo, em que as identidades são maleáveis e sujeitas a constantes trocas e modificações, gerando estilos, modos de ser e visões de mundo próprias e particular a cada grupo social.

A teoria sociológica de Elias nos permite construir análises que incorporam alguns grupos sociais que reivindicam, das ciências sociais, a observação de suas posições sociais e visões de mundo particulares, por exemplo, os grupos juvenis e os movimentos de mulheres. Seus estudos sobre as sociedades cortesãs e mesmo sobre as sociedades modernas, como faz em Os alemães, tratam das desigualdades de poder que também se estabelecem entre os sexos e entre diferentes grupos etários.

Como bem assinalou Zabludovsky (2007, p. 137-148), em seus estudos Elias discorre sobre as transformações familiares, as mudanças nas relações entre o público e o privado, as transformações na vida cotidiana, na intimidade e nos padrões de julgamento moral e estético. 
A força do pensamento sociológico de Norbert Elias, segundo a autora, que justifica sua pertinência para os estudos das sociedades contemporâneas está em algumas, porém fundamentais, ideias-força que sustentam todo o edifício teórico de sua obra: a artificialidade e arbitrariedade da separação entre "indivíduo" e "sociedade" e, por conseguinte, a interdependência entre os processos sociológicos, ou político-sociais, e os processos psicológicos, ou socioindividuais. Ao objetar a separação entre o "micro" e o "macro", denuncia a artificialidade das distinções entre "ator" e "estrutura", entre "ação" e "sistema", propondo mudar o olhar da "coisa em si", ou seja, do "fato" ou "fenômeno" social, para as "relações entre si". Isso nos permite extrapolar as categorias clássicas da ciência social e enxergar a multiplicidade de formas sociais (figurações) e a enxergar mais os processos, desconstruindo supostas formas cristalizadas de entender a sociedade e de classificar o "social", ou seja, nos permite trabalhar com novas categorias, novas identidades e novos processos sociais atuantes no presente.

No entanto, o horizonte do trabalho sociológico de Elias também tem limitações, como bem observa a autora em relação à ausência da religião nos estudos de Elias sobre a formação da sociedade burguesa europeia:

"No deja de sorprender que en El proceso de la civilización no se pondere la im-
portancia de la religión en el desarrollo histórico de la autocontención personal
y social con el consecuente surgimiento del 'sentimiento de vergüenza'. Cabe
preguntar al respecto: como se puede llegar a explicar éste sin tener presente el
enorme papel que históricamente ha tenido 'la culpa religiosa'?” (ZABLUDO-
VSKY, 2007: 145).

É perceptível que a objeção da socióloga mexicana não se reduz a denunciar a ausência de uma temática qualquer, como a requerer do autor uma análise que foi abordada por outros autores clássicos. Não, ela não está a requerer uma análise das religiões. A sua objeção é mais profunda e ela se surpreende como que, para um autor cuja teoria funda-se na importância das relações de interdependência, na indissociabilidade entre as questões "macro" e "micro", entre a sociogênese e a psicogênese, como que justamente esse autor deixou de considerar as relações entre a constituição psicossocial da sociedade burguesa com a religião católica e a protestante, se essas relações incidem diretamente na formação de padrões de comportamento social? E como ignorar as relações entre as igrejas e os Estados nacionais na formação da sociedade burguesa europeia?

Para sermos objetivos, tomamos "carona" nessa crítica à omissão de Elias a respeito das relações entre religião, comportamento social e Estado, para denunciar outra omissão da mesma envergadura: a omissão de Elias acerca das relações entre as sociedades europeias e as sociedades coloniais que, no período histórico que compreende os seus estudos sobre a formação social europeia, também foram relações que marcaram tanto a sociogênese quanto a psicogênese das sociedades envolvidas. Como é possível ignorar as relações entre colonizadores e colonizados quando o empreendimento colonial, em toda a sua magnitude, está ancorado na desumanização do colonizado e do escravizado? E, ainda mais, 
como ignorar essas relações, quando o próprio Elias revela que, na relação, os senhores se tornam escravos de si próprios e se desumanizam também?

Apesar de demonstrar profunda preocupação com a humanidade, evidenciada em inúmeras obras e no que podemos chamar de sua filosofia política, apesar disso, a questão das relações colonizadores (europeus) e colonizados (americanos, africanos e asiáticos), assim como as relações com a religiosidade, não se constituíram em objeto de estudo para o sociólogo alemão. Discutiremos os efeitos dessa omissão no campo dos estudos sobre educação. ${ }^{1}$

\section{A alternativa decolonial para a EduCAÇão}

Os efeitos do trabalho dos colonizadores não se encerraram com o fim do período da colonização. A herança cultural se revela forte na língua e na forma de estruturar a linguagem, que é o pensamento. Pensar com as ferramentas da língua do colonizador e da racionalidade lógica do colonizador é o maior triunfo deste sobre os povos colonizados. Para além disso, as questões relacionadas à divisão internacional do trabalho e todo um conjunto de questões geopolíticas foram reconfigurados no mundo do pós-guerra, "E então, surpreendentemente, o mundo inteiro se descolonizou depois da Segunda Guerra Mundial" (SAID, 2005, p. 253). Essas mudanças suscitaram um conjunto de teorizações de autores, cujos estudos ficaram conhecidos como pós-coloniais, por exemplo, Edward Said (1995), Stuart Hall (1997), Homi Bhabha (1999) e entre outros.

Mas, esses autores ainda tomaram como ponto de partida as escolas de pensamento europeia e norte-americana, retomando a discussão do multiculturalismo, que propõe a convivência respeitosa e harmoniosa de diferentes tradições culturais dentro de uma sociedade coesa. O multicuralismo não é uma proposição política unificada e coesa, ao contrário, sob esse rótulo se abrigam diferentes concepções relacionadas com o pensamento conservador, liberal, crítico, pluralista, socialista etc. Mesmo assim, possibilitou trazer a cultura para o palco da política, o que é um avanço diante da separação artificial e falsa entre cultura e política, ainda muito presente no pensamento liberal e neoliberal.

Mas, mesmo a proposta multicultural emanada do pensamento pós-colonial evitou enfrentar as tensões que foram geradas historicamente no processo de colonização e que não desaparecem no ar. Também não enfrentou a questão do monopólio epistemológico do pensamento racionalista-científico no sistema escolar e acadêmico.

Para Zizek (2008), o multiculturalismo é uma forma de racismo "com respeito", de convivência elegante, que permite ao europeu e ao norte-americano apreciar e reconhecer outras culturas inferiores às suas, e tratar os nativos com o mesmo tratamento que o coloni-

1 Como todo trabalho de pesquisa, essa reflexão "não-acabada" vem sendo desenvolvida ao longo dos anos recentes, justamente no trabalho de confrontação de dados empíricos com textos interpretativos das teorias de Norbert Elias - Gina Zabludovsky, Stephen Mennel, Eric Dunning, Ademir Gebara, entre outros - e do pensamento decolonial - Anibal Quijano, Silvia Rivera Cusicanqui, Walter Mignollo, Catherine Walsh, entre outros. A reflexão, neste artigo, procura delimitar-se às implicações e efeitos das teorias em questão sobre o campo da educação, devendo, em outro artigo, estender-se às questões epistemológicas das ciências sociais. 
zador dispensava ao colonizado, de forma condescendente e respeitosa.

Enquanto pensamento político, o multiculturalismo não causou muitos danos à hegemonia da cultura europeia e norte-americana sobre todas as demais, instaladas que estão nos sistemas científico e escolar.

Outros pesquisadores, especialmente latino-americanos, mas também africanos e indianos, entendendo os limites do pós-colonialismo, que não percebia como o colonialismo se modificara na medida em que as condições históricas das relações entre os povos se alteravam, cunharam o conceito de colonialidade, que seria expressão da reconfiguração da herança colonial em nossas sociedades. Segundo Maldonado-Torres, a colonialidade é

[...] un patrón de poder que emergió como resultado del colonialismo moderno, pero que en vez de estar limitado a una relación formal de poder entre dos pueblos o naciones, más bien se refiere a la forma como el trabajo, el conocimiento, la autoridad y las relaciones intersubjetivas se articulan entre sí, a través del mercado capitalista mundial y de la idea de raza. Así, pues, aunque el colonialismo precede a la colonialidad, la colonialidad sobrevive al colonialismo. La misma se mantiene viva en manuales de aprendizaje, en el criterio para el buen trabajo académico, en la cultura, el sentido común, en la auto-imagen de los pueblos, en las aspiraciones de los sujetos, y en tantos otros aspectos de nuestra experiencia moderna. En un sentido, respiramos la colonialidad en la modernidad cotidianamente (2007, p. 131).

A colonialidade, segundo Maldonado-Torres, se expressaria em três dimensões distintas, porém entrelaçadas. A primeira seria a colonialidade do poder, que está presente na hierarquização racial da sociedade, gerando processos de inferiorização cultural. Outra seria a colonialidade na dimensão do saber, que se manifesta na imposição de uma única epistemologia válida como verdade, como conhecimento válido, ancorada na racionalidade científica. É essa a epistemologia que organiza todos os sistemas de ciência e de ensino nas sociedades modernas, seja na América Latina, África ou Ásia, ignorando completamente os saberes e conhecimentos dos povos originais e minorias étnicas locais. Para Grosfoguel, a "epistemologia eurocêntrica ocidental dominante não admite nenhuma outra epistemologia como espaço de produção de pensamento crítico nem científico" (2007, p. 35).

A terceira dimensão está no nível do ser, fruto da interiorização da hierarquia racial, da negação histórica dos não europeus como sujeitos de direitos, ideias e atuantes na construção do mundo, a colonialidade do ser se daria no nível da intersubjetividade, produzindo imagens e autoimagens de inferioridade de si diante da superioridade do colonizador. Isto se manifestaria não no nível da consciência, mas inconscientemente, com incorporação de desejos e projeções que refletem valores e visões de mundo originárias do colonizador. ${ }^{2}$

Concordando com Maldonado-Torres, Catherine Walsh (2005) coloca a colonialidade

2 Devemos ser cautelosos quanto à noção de colonialidade do ser. De acordo com José Jorge de Carvalho, em palestra proferida na Universidade de Brasília durante o Seminário Narrativas Educativas Decoloniais, em 14 de junho de 2017. Disse ele que a colonialidade não opera no nível do ser, mas no nível da existência, da experiência. Portanto, se o ser é inferiorizado por forças externas, o ser não é subalterno, mas subalternizado. 
do ser como um conceito denúncia, em reação à negação histórica da condição humana aos povos não europeus, um conceito que teria origem na leitura de Fanon pelos intelectuais do pensamento decolonial. Fanon, na obra Os condenados da terra (2013), denunciou a demonização desses povos pelos europeus e norte-americanos, projetando sobre os "outros" todas as imagens do mal, dos sem valores, sem ética, portanto, do ser desumano, e, por isso, desprezível e descartável.

Para Mignolo (2005, p. 75), "a colonialidade é constitutiva da modernidade, e não derivada". A aposta do pensamento decolonial é justamente buscar construir conhecimento crítico da modernidade nas matrizes de conhecimentos dos povos não ocidentais que foram silenciadas, inferiorizadas e excluídas do sistema acadêmico. É uma tarefa totalmente diferente das propostas da pós-modernidade, do pós-estruturalismo, do pós-marxismo, que continuam tendo como referência primordial o pensamento ocidental, pois busca autores e textos não-ocidentais. E também procura refletir acerca das experiências passadas e atuais de articulação de epistemologias, a exemplo do que fez o Exército Zapatista na releitura do marxismo e sua adaptação deste à cosmovisão ameríndia.

Por isso, outro conceito importante no aparato teórico-metodológico do pensamento pós-colonial é o de pensamento de fronteira, a exemplo do que fizeram os zapatistas. Segundo Walsh $(2005,2006)$, o pensamento de fronteira não rompe com o pensamento hegemônico, mas o submete à tensão e questionamento de outras fontes de conhecimento. Dessa forma, introduz elementos outros, provoca fissuras, altera, provoca intervenções na ordem do saber, gerando negociações e embates no que ela considera como luta epistemológica.

Esses diálogos e confrontos entre epistemologias, apesar de permitir a formação de alianças estratégicas entre povos subalternizados, colocando em cooperação e colaboração epistêmica intelectuais latino-americanos, africanos, indianos. De modo diferente do pensamento pós-colonial, o pensamento decolonial aposta na interculturalidade.

De acordo com José Jorge de Carvalho, em palestra proferida no Seminário Narrativas Educativas Decoloniais (UnB, Brasília, 12 a 14/06/2017), a interculturalidade, ao aproximar as diferenças, também produz embates e resistências. Ela não busca a posição neutra ou harmônica, como a multiculturalidade. Mas é uma resposta veemente contra a monoculturalidade característica das sociedades onde impera o racionalismo-científico da modernidade/colonialismo.

A interculturalidade, necessariamente, não precisa produzir traduções, sínteses, embora possa também fazer isso. Diante das incompatibilidades - de valores, de pressupostos, de horizontes -, a interculturalidade pode produzir acordos de convivência e, simultaneamente, manter as tensões linguísticas. Também admite a possibilidade da incomensurabilidade, ou seja, de determinados conhecimentos que não podem ser articulados a outros, por não haver "pontes" - conceitos, ideias, palavras - que expressem seus significados quando fora do seu contexto de aplicação.

Para Walsh (2006), a interculturalidade se expressa como articulação de conhecimentos, saberes e práticas culturalmente diferentes em processo dinâmico, criativo e comunicativo, calcado no respeito e legitimidade mútuos. É também espaço de negociação, de 
tradução, de conflitos e tensões que a interculturalidade está intimamente relacionada com a construção de

[...] um projeto social, cultural, educacional, político, ético e epistêmico em direção à decolonização e à transformação. É um conceito carregado de sentido pelos movimentos sociais indígenas latino-americanos e que questiona a colonialidade do poder, do saber e do ser. Enfim, ele também denota outras formas de pensar e se posicionar a partir da diferença colonial, na perspectiva de um mundo mais justo.

É nesse sentido que a interculturalidade não é compreendida somente como um conceito ou termo novo para referir-se ao simples contato entre o ocidente e outras civilizações, mas como algo inserido numa configuração conceitual que propõe um giro epistêmico capaz de produzir novos conhecimentos e outra compreensão simbólica do mundo [...] (OLIVEIRA, CANDAU, 2010, p. 27).

A ideia de giro epistêmico sugere o reordenamento da geopolítica do conhecimento, a começar pelo campo educativo. Apesar de poder contribuir significativamente na reconfiguração dos currículos educacionais, o pensamento decolonial propõe transformar os fundamentos centrais do projeto de Modernidade/Colonialidade, que sustenta a "manutenção da ordem hierárquica racial, histórica e atual, na qual os brancos e especialmente os homens brancos europeus permanecem como superiores" (WALSH, 2007, p. 9).

O giro epistêmico seria conduzido pela introdução da interculturalidade nos sistemas científico e escolar, provocando a quebra da monocultura epistêmica, onde o "outro" é sempre tomado como objeto de estudo, e da monologia do conhecimento escolar, sempre voltado a reproduzir o conhecimento científico. No bojo do projeto intercultural, o professor e a pedagogia também seriam interculturais (CARVALHO, 2017).

Portanto, de modo diferente das proposições multiculturais que não tensionam a matriz eurocêntrica nos sistemas de ciência e de ensino, nem questionam as bases ideológicas do Estado-nação, limitando-se apenas à inclusão da diversidade cultural nos sistemas político e educacional, a perspectiva da interculturalidade sugere uma recriação da pedagogia, a partir do paradigma crítico decolonial.

A interculturalidade crítica (...) é uma construção de e a partir das pessoas que sofreram uma experiência histórica de submissão e subalternização. Uma proposta e um projeto político que também poderia expandir-se e abarcar uma aliança com pessoas que também buscam construir alternativas à globalização neoliberal e à racionalidade ocidental, e que lutam tanto pela transformação social como pela criação de condições de poder, saber e ser muito diferentes. Pensada desta maneira, a interculturalidade crítica não é um processo ou projeto étnico, nem um projeto da diferença em si. (...), é um projeto de existência, de vida (WALSH, 2007, p. 8). 


\section{CONSIDERAÇões FINAIS}

A teoria dos processos civilizadores e todos os conceitos e noções que legamos do pensamento de Norbert Elias possibilitam à pesquisa em educação tratar de ampla gama de temas e problemas presentes na educação e nos sistemas escolares das realidades que vivemos no Brasil e em outros países da América Latina.

Com a teoria dos processos civilizadores, Elias reconstitui o longo caminho de formação das sociedades europeias, revelando as interdependências entre a constituição das macroestruturas sociais - classes governantes, instituições de Estado, códigos jurídicos etc. - e das estruturas psíquicas que formam as subjetividades e modelam os comportamentos adequados às normas sociais que regulam a vida cotidiana. Ademais, vemos outras possibilidades de aplicação de conceitos e noções que circulam em sua teoria, relacionados aos estudos das figurações e interdependências, como habitus, trajetórias, equilíbrio de poder, relações entre estabelecidos e novatos, que apontam para caminhos investigados que considerem fatores pouco visibilizados em pesquisas, mas que são elementos importantes na compreensão das relações sociais. Como exemplo, podemos ver como a fofoca cumpria uma função organizadora e de controle na comunidade retratada no livro Os estabelecidos e os outsiders. Assim como as emoções na vida de Mozart, marcado pelo ciúme da esposa que o abandonou, pela memória da rigidez que foi tratado pelo pai na infância e pela frustração por não ter conseguido viver como um músico independente da corte. Do mesmo modo, Elias nos oferece ferramentas analíticas para transitar entre o micro e o macro, para articular as dimensões políticas, sociais, culturais e psicossociais na investigação científica.

Quando aplicamos esse referencial ao vasto campo da pesquisa em educação, claramente podemos perceber sua contribuição para reconstituir o caminho de formação dos sistemas educativos, que é um primeiro e importante passo para a elaboração crítica sobre os problemas relacionados à escola, seja nas áreas de currículo, formação de professores, relações de poder na comunidade escolar, práticas educativas, disciplina, organização escolar, da educação das crianças e dos jovens etc.

Como vimos no texto, também podemos caminhar com os referenciais de Elias nas pesquisas sobre trajetórias escolares e o "peso" dessas trajetórias na vida dos jovens. Podemos ainda tratar das questões de geração, dos conflitos intergeracionais, das questões acerca da inserção de jovens no mercado profissional, e das questões da formação não escolar por meio das redes de sociabilidade dos jovens. E, ainda, estudar a respeito de violências e processos que serão chamados de descivilizadores (GEBARA, 2011).

Mesmo com todo esse amplo leque de possibilidades, não é possível caminhar com Elias quando se trata de se aprofundar nos problemas relacionados à educação monocultural que é característica dos sistemas educativos constituídos sob a égide da modernidade. Mesmo tendo realizado uma pesquisa de longa duração sobre o processo civilizador europeu, Elias não incluiu as questões do colonialismo em seu núcleo de interesse. Isto, apesar do fato do processo colonizador europeu ter se estendido do século XVI ao XX e que, durante esse período, especialmente nos dois ou três séculos do início da colonização, o fluxo 
de pessoas que iam e voltavam entre o novo e o velho continente, inclusive de índios e negros que eram levados para serem exibidos nas cortes, não tenha sido assim tão desprezível. O que atravessou e atravessa a história dos encontros entre os povos e as culturas foi a marca da superioridade eurocêntrica, como nos ensina Michel de Certeau: "O conquistador irá escrever o corpo do outro e nele traçar a sua própria história” (1982, p. 9).

Elias se interessou por estudar e oferecer uma explicação aos processos violentos ocorridos na Europa, especialmente a respeito da guerra e o nazismo, chamando-os de processos descivilizadores. Mas não demonstrou muito interesse pelos séculos de violência europeia sobre os povos colonizados da América, África e Ásia.

Não sendo seu núcleo de interesse e ignorando as questões relativas às relações colonizador-colonizado, que também são questões que afetam a estruturação das relações sociais e dos padrões de sentimento e comportamento dos europeus, não é com Elias que iremos nos aprofundar acerca das questões das heranças do colonialismo e dos seus efeitos sobre alguns dos problemas mais importantes da agenda política e educacional atualmente, que é a relacionada às questões raciais e à diversidade cultural.

O legado do colonialismo em nossas sociedades é a colonialidade arraigada em nossas visões de mundo, modos de pensar e agir, modos de julgar e de escolher o que vestir, para onde viajar etc. A colonialidade nasce atrelada ao projeto da modernidade, e é esse projeto que modela os sistemas políticos, sociais, jurídicos, científicos e educacionais das sociedades que experimentaram o colonialismo.

O colonizador foi expulso dos territórios, mas não foi expulso dos corpos. O sistema escolar é reprodutor desse sistema, está mergulhado no pensamento racionalista-científico nascido na experiência europeia. O giro epistemológico que propõe o pensamento decolonial oferece, para a pesquisa e as políticas em educação, elementos para detectar e tratar do monoculturalismo das práticas, do currículo, da organização e da forma escolar, dos materiais pedagógicos e paradidáticos, enfim, do aparelho institucional e do aparato tecnológico que tem servido a perpetuar a negação dos conhecimentos e culturas que fazem parte de amplas parcelas da população brasileira e latino-americana.

Os conceitos de colonialidade - do poder, do saber e do ser - e de interculturalidade são os instrumentos para introduzir outras epistemologias necessárias para quebrar a monologia do conhecimento escolar e construir um projeto intercultural para a escola, uma pedagogia intercultural que agregue conhecimentos e saberes, sem prejuízo dos conhecimentos científicos, que já são patrimônio cultural de toda a humanidade. Esse projeto também será agregador dos sujeitos excluídos e marginalizados, fora e dentro da escola. Um projeto em que seja possível conviver as diferenças, e que admita que nem todos precisam aprender as mesmas coisas, mas todos devem aprender e ensinar algumas coisas.

Desconstruir essa armadilha civilizatória é imperativo e imprescindível para os sujeitos e sociedades que vislumbram a pluralidade e a polifonia de culturas e saberes, como base para gerar processos democráticos em condições de menor desigualdade social e maior equidade nas relações entre os grupos sociais entre si e com o aparelho estatal, e reconstruir as formas de gerir o comum (a política). 


\section{REFERÊNCIAS}

ABRAMOWICZ, Anete; GOMES, Nilma Lino Gomes (Orgs.). Educação e raça - Perspectivas políticas, pedagógicas e estéticas. São Paulo: Autentica, 2010.

ARENDT, H. A crise na educação. In: ARENDT, H. Entre o passado e o futuro, 4. ed. São Paulo: Perspectiva, 1997.

ARIÈS, Phillipe. História social da criança e da família, 2. ed. Rio de Janeiro: LTC, 1981.

BHABHA, Homi. O local da cultura. Belo Horizonte: Editora UFMG, 1999.

BOURDIEU, Pierre. A Distinção. Crítica Social do Julgamento, 2. ed. São Paulo: Edusp Zouk. Porto Alegre: Zouk, 2007.

BOURDIEU, P., PASSERON, J-C. A reprodução: elementos para uma teoria do sistema de ensino. Petrópolis: Vozes, 2008.

CANARIO, Rui. O que é a escola? Um olhar sociológico. Cidade do Porto: Porto Ed., 2005.

CARVALHO, José Jorge de. Como a universidade pode se tornar intercultural?. Palestra (notas pessoais). Seminário Narrativas Educativas Decoloniais. Brasília, Auditório Candango, Faculdade de Educação/UnB, 12 a 14/06/2017.

CAVALLEIRO, Eliane dos Santos. Discriminação racial e pluralismo em escolas públicas da cidade de São Paulo. In: BRASIL, Educação anti-racista: caminhos abertos pela Lei Federal n. 10.639/03. Brasília: Ministério da Educação, 2005, p. 65-104.

CHARTIER, Roger. Formação social e economia psíquica: a sociedade de corte no processo civilizador. In: ELIAS, N. A sociedade de corte. Prefácio. Rio de Janeiro: Zahar, 2001.

DE CERTEAU, Michel. A escrita da História. São Paulo: Forense Universitária, 1982.

DUSSEL, Enrique. Europa, modernidade e eurocentrismo. In: LANDER, E. (Org.). A Colonialidade do Saber: eurocentrismo e ciências sociais. Perspectivas latino-americanas, p. 55-70. Buenos Aires: Colección Sur, CLACSO, 2005. Disponível em http://bibliotecavirtual.clacso.org.ar/ar/libros/lander/pt/Dussel.rtf . Acesso em: 5 jul. 2016.

ELIAS, Norbert. O processo civilizador: uma história dos costumes, v. 1. Rio de Janeiro: Jorge Zahar Ed., 1994a.

. A sociedade dos indivíduos. Rio de Janeiro: Jorge Zahar Ed., 1994b.

. Os alemães. A luta pelo poder e a evolução do habitus nos séculos XIX e XX. Rio de Janeiro: Jorge Zahar Ed., 1997. 
1998.

. La civilización de los padres y otros ensayos. Bogotá: Grupo Editorial Norma, . Teoria simbólica. Oeiras: Celta, 2002.

FANON, Frans. Os condenados da terra, $2^{\text {a }}$. reimpressão atualizada. Juiz de Fora (MG): Editora UFJF, 2013.

GEBARA, Ademir. Civilização e descivilização na América Latina: catequizar e domesticar ou ensinar e educar. Cadernos de Estudos Sociais. Recife, v. 26, n. 1, jan./jun. 2011, p. 21-32.

GROSFOGUEL, Ramon. Dilemas dos estudos étnicos norte-americanos: multiculturalismo identitário, colonização disciplinar e epistemologias decoloniais. Ciência e cultura. São Paulo: v. 59, n. 2, p. 32-35, 2007.

HALL, Stuart. Identidades culturais na pós-modernidade. Rio de Janeiro: DP\&A, 1997. 2003. . Da diáspora: identidades e mediações culturais. Belo Horizonte: Ed UFMG,

LIMA, Joana D'Arc de S. Cartografia das artes plásticas no Recife dos anos 1980. Recife: Ed. Universitária UFPE, 2014.

MALDONADO-TORRES, Nelson. Sobre la colonialidad del ser: contribuciones al desarrollo de un concepto. In: CASTRO-GÓMEZ, S.; GROSFOGUEL, R. (Orgs.). EI giro decolonial. Reflexiones para una diversidad epistémica más allá del capitalismo global. Bogotá: Universidad Javeriana-Instituto Pensar, Universidad Central-IESCO, Siglo del Hombre Editores, 2007, p. 127-167.

MARQUES, Vera R. Beltrão. A medicalização da raça: médicos, educadores e discurso eugênico. Campinas: Unicamp, 1994.

MIGNOLO, Walter. A colonialidade de cabo a rabo: o hemisfério ocidental no horizonte conceitual da modernidade. In: LANDER, E. (Org.). A colonialidade do saber: eurocentrismo e ciências sociais. Perspectivas latino-americanas. Buenos Aires: Clacso, 2005, p. 71-103.

MOTA, André. Higienizando a raça pelas mãos da educação ruralista: o caso do Grupo Escolar Rural do Butantan em 1930. Interface: comunicação, saúde, educação. São Paulo, 13 (32), 2010, p. 221-227.

OLIVEIRA,LuisFernandes de; CANDAU, Vera M.F.Pedagogia decolonial e educação antirracista e intercultural no Brasil. Educação em revista, v. 26, n. 1, Belo Horizonte, abr. 2010. Disponível em http://dx.doi.org/10.1590/S0102-46982010000100002. Acesso em 16 maio 2017.

O SEMEADOR. Órgão oficial dos alunos da Escola Rural Modelo. Ano 4, n. 4, mai. 1935, p. 1. 
PÉREZ GÓMEZ, A. I. As Funções Sociais da Escola: da reprodução à reconstrução crítica do conhecimento e da experiência. In: GIMENO SACRISTÁN, J.; PÉREZ GÓMEZ, A. I. Compreender e Transformar o Ensino, 4. ed. Porto Alegre: ArtMed, 1998.

RODRIGUES, Zita A. Lago. Paradigma da ciência, do saber e do conhecimento e a educação para a complexidade: pressupostos e possibilidades para a formação docente. Educar, 2008, Curitiba, Editora UFPR, n. 32, p. 87-102.

SAID, Edward. W. Cultura e imperialismo. São Paulo: Companhia das Letras, 1995.

. Representações do intelectual. São Paulo: Companhia das Letras, 2005.

SAVIANI, Demerval. Educação: do senso comum à consciência filosófica. São Paulo: Cortez Autores Associados, 1980.

SOUSA, Francisca M. do Nascimento. Linguagens escolares e reprodução do preconceito. In: BRASIL, Educação anti-racista: caminhos abertos pela Lei Federal n. 10.639/03. Brasília: Ministério da Educação, 2005, p. 105-120.

TAVARES, Mauricio Antunes. De aprendiz a sabedor: os jovens e as mudanças sociais no mundo rural. In: JUNQUEIRA, Lilia (Org.). Cultura e classes sociais na perspectiva disposicionalista. Recife: Ed. Universitária UFPE, 2010, p. 305-356.

. Entrelaçamentos entre campo de possibilidades e trajetórias de vida: a questão da escolarização dos jovens no interior de Pernambuco. Cadernos de Estudos Sociais, v. 26, n. 1, Recife, jan./jun. 2011, p. 121-133.

. Para livrar o campo do amarelão, da maleita, do alcoolismo e do ofidismo. A educação rural em Pernambuco nos anos 1930 a 1950. Educar em revista, n. 54, Curitiba, Ed. UFPR, 2014, p. 141-158.

. Um olhar para a Sociologia da Juventude a partir dos conceitos de geração e moratória social. In: SILVA, T. A. A. (Org.). As juventudes e seus diferentes sujeitos. Recife: Editora da Universidade Federal Rural de Pernambuco, 2017, p. 21-43.

WALSH, Catherine. Pensamiento crítico y matriz (de)colonial. Reflexiones latinoamericanas. Quito: Ediciones Abya-yala, 2005, p. 13-35.

. "Interculturalidad y colonialidad del poder. Un pensamiento y posicionamiento 'otro' desde la diferencia colonial." In: WALSH, C.; LINERA, A. G.; MIGNOLO, W. Interculturalidad, descolonización del estado y del conocimiento. Buenos Aires: Del Signo, 2006, p. 21-70.

. Interculturalidad Crítica/Pedagogia decolonial. In: Memórias del Seminário Internacional "Diversidad, Interculturalidad y Construcción de Ciudad", Bogotá: Universidad Pedagógica Nacional 17-19 de abril de 2007.

ZABLUDOVSKY, Gina. Norbert Elias y los problemas actuales de la sociología. México (D.F.): FCE, 2007. 
ZIZEK, Slavoj. En defensa de la intolerancia. Madrid: Sequitur, 2008.

DADOS DOS AUTORES:

\section{Mauricio Antunes Tavares}

Doutor em Sociologia (UFPE-2009), Pesquisador Titular na Fundaj e Professor do Programa Associado de Pós-Graduação em Educação, Cultura e Identidades. Universidade Federal Rural de Pernambuco (Fundação Joquim Nabuco - FUNDJ), Recife/PE. Brasil

\section{Joana D'Arc de Sousa Lima}

Professora adjunta na UNILAB Universidade da Integração Internacional da Lusofonia Afro-Brasileira, Campus Redenção, Ceará.

Submetido em: 20/08/2017

Aceito em: 05/03/2018 